\title{
Genèse du film La Chambre noire d'Adama Kouyaté
}

Alain Turpault

\section{OpenEdition}

Journals

Édition électronique

URL : https://journals.openedition.org/coma/413

DOI : $10.4000 /$ coma.413

ISSN : 2275-1742

\section{Éditeur}

Institut des textes \& manuscrits modernes (ITEM)

\section{Référence électronique}

Alain Turpault, "Genèse du film La Chambre noire d'Adama Kouyaté », Continents manuscrits [En ligne],

3 | 2014, mis en ligne le 08 novembre 2014, consulté le 12 janvier 2023. URL : http:// journals.openedition.org/coma/413; DOI : https://doi.org/10.4000/coma.413

Ce document a été généré automatiquement le 12 janvier 2023.

\section{(c) (i) ()}

Creative Commons - Attribution - Pas d'Utilisation Commerciale - Pas de Modification 4.0 International - CC BY-NC-ND 4.0

https://creativecommons.org/licenses/by-nc-nd/4.0/ 


\title{
Genèse du film La Chambre noire d'Adama Kouyaté
}

\author{
Alain Turpault
}

\section{NOTE DE L'AUTEUR}

Note technique : n'ayant pas voulu utiliser la fonction night shoot de ma caméra, j'ai fait le choix d'une image saturée de bruit, cela lui donne une matière presque argentique et incandescente.

\section{Un photographe méconnu}

1 Natif de Bougouni au sud du Mali, âgé de 82 ans, Adama Kouyaté vit actuellement à Ségou et n'exerce plus d'activité depuis plusieurs années.

Il a fait ses premiers apprentissages auprès de Bakary Doumbia à Bamako. En 1947, il entre comme préposé à l'agrandisseur chez Pierre Garnier, le " maître blanc » des photographes de Bamako. C'est en 1949 qu'il ouvre son premier studio à Kati située à 15 km de Bamako et le baptise : «Photo Hall Kati ».

Quelques années plus tard, il devient chauffeur routier car la photographie ne suffit pas à subvenir à ses besoins. En 1964, il s'installe à Ouagadougou pour y ouvrir pendant une année un nouveau studio, le «Photo Hall Voltaïque ». Puis il ouvre un troisième studio à Bouaké en Côte d'Ivoire, qui fonctionnera jusqu'en 1968. Le 22 septembre 1969, il inaugure son dernier studio à Ségou, où il possédait une maison depuis 1954, le « Photo Hall d'Union ».

3 Ses portraits en noir et blanc, réalisés principalement avec un Rolleiflex (Tessar $75 \mathrm{~mm}$ $\mathrm{f}: 3,5)$ étaient plus sobres dans les postures des personnages et dans l'utilisation des fonds tendus à l'arrière plan des sujets que ceux de Malick Sidibé par exemple. Ils seraient plus proches, pour moi, de ceux de Abdourahmane Sakaly. Les images de Adama Kouyaté sont d'une très belle qualité technique, j'ai vu des tirages de 100 x 100 
$\mathrm{cm}$ réalisés par le laboratoire Picto Bastille, remarquables. Adama Kouyaté mérite d'occuper une place d'honneur dans l'histoire de la photographie de studio de l'Afrique de l'ouest.

\section{Histoire d'une rencontre}

4 J'ai eu la chance de rencontrer Adama Kouyaté en 2010 à Ségou.

Bel homme de solide facture (c'est un ancien boxeur), il a toujours été cependant très modeste et affable. Alors que je lui rendais visite, il me demanda si je pouvais apporter des tirages photographiques à un parent vivant à Bamako lors de mon retour vers la France. Ce que j'acceptai bien volontiers.

5 Il me donna rendez-vous le lendemain soir à $21 \mathrm{~h}$ car il devait réaliser les tirages en question dans son laboratoire et me proposa d'assister à la séance dans sa chambre noire. Ce qui m'enchanta.

Le soir venu j'apportai avec moi une petite camera numérique DV et j'ai pu enregistrer toute la séance de travail. Il s'agissait presque d'un long plan séquence, j'ai fait quelques coupes parce que connaissant bien le déroulement du tirage argentique, j'ai $\mathrm{pu}$ anticiper ses gestes et lui épargner des interruptions. La porte du petit laboratoire (2x2m) était restée ouverte sur la nuit étoilée et la température des bains devait avoisiner les $25^{\circ}$. Après avoir recherché assez longuement dans les pochettes Kodak le négatif en question, il le trouva avec soulagement. Je remarquai tout de même son sens de l'organisation malgré le peu d'espace de rangement. Ses négatifs étaient classés dans des pochettes, elles-mêmes rangées dans des boîtes de papier de différentes marques jaunies et poussiéreuses, mais tout ce "trésor " comme l'appelle Adama est bien là ; toute une vie de photographe. Il ne possédait que trois feuilles $30 \times 40 \mathrm{~cm}$ et une demie feuille pour les essais. Il a travaillé sans margeur en comptant de tête les secondes nécessaires à l'exposition - «je me trompe rarement », dit-il. Il faisait très chaud, Adama était torse nu, j'observais son matériel et particulièrement son agrandisseur Krokus dont le soufflet avait été réparé à maintes reprises; les cuvettes étaient recouvertes d'un important dépôt d'argent, le révélateur était oxydé, presque noir, mais tout cela semblait très bien fonctionner et donner les meilleurs résultats escomptés par l'auteur. J'ai ressenti chez Adama une certaine fierté légitime au moment du rinçage final, quand il présenta les trois épreuves encore ruisselantes; « c'est magnifique » dit-il avant de déclarer : « la séance est terminée ».

6 Grace aux éditions Gang, on peut aujourd'hui consulter dans un très beau livre intitulé studios d'Afrique la première monographie de ce très attachant personnage, dont l'œuvre faite de retenue et de rigueur impressionne l'amateur de portraits en studio en Afrique.

7 Le film est disponible ici. 
INDEX

Mots-clés : Kouyaté Adama, photographie, Mali, Bamako, atelier, tirage photographique Index géographique : Bamako, Mali

\section{AUTEUR}

ALAIN TURPAULT

Auteur-photographe 